\title{
Recent progress in the study of the interactions of amphotericin B with cholesterol and ergosterol in lipid environments
}

\author{
Daniel Michał Kamiński
}

Received: 25 April 2014 / Revised: 8 August 2014 / Accepted: 19 August 2014 / Published online: 31 August 2014

(C) The Author(s) 2014. This article is published with open access at Springerlink.com

\begin{abstract}
In the past decade substantial progress has been made in understanding the organization and biological activity of amphotericin B (AmB) in the presence of sterols in lipid environments. This review concentrates mainly on interactions of AmB with lipids and sterols, AmB channel formation in membranes, AmB aggregation, AmB modifications important for understanding its biological activity, and AmB models explaining its mechanism of action. Most of the reviewed studies concern monolayers at the watergas interface, monolayers deposited on a solid substrate by use of the Langmuir-Blodgett technique, micelles, vesicles, and multi-bilayers. Liposomal AmB formulations and drug delivery are intentionally omitted, because several reviews dedicated to this subject are already available.
\end{abstract}

Keywords Amphotericin B - Cholesterol - Ergosterol · Lipids · Aggregation · Pore formation · Review

\section{Introduction}

Amphotericin B (AmB) is a macrolide polyene antifungal antibiotic (Gallis et al. 1990; AbuSalah 1996; Hartsel and Bolard 1996; Carrillo-Munoz et al. 2006; Cereghetti and Carreira 2006). The number of research papers published in recent years on its pharmacological properties, clinical therapeutic effects, and toxicity is evidence of the importance of AmB in contemporary medicine (Brajtburg et al. 1990; Tiphine et al. 1999; Fanos and Cataldi 2000; Lemke et al. 2005; Fanos et al. 2007; Moen et al. 2009; Hamill

D. M. Kamiński $(\bowtie)$

Department of Chemistry, University of Life Sciences in Lublin, Akademicka 15, 20-950 Lublin, Poland

e-mail: daniel_kaminski3@wp.pl
2013). AmB, a metabolite of Streptomyces nodosus, causes disintegration of the fungal lipid membranes. These membranes contain ergosterol, which, similar to cholesterol, changes dynamic properties and stabilizes lipid bilayer structure. AmB has better selectivity for membranes containing ergosterol than for those containing cholesterol. This property enables use of the drug to treat deep fungal infections that occur in the aftermath of AIDS or transplantation. Despite its antifungal activity, AmB has many sides effects which are most probably related to AmB-cholesterol interactions (Wilcock et al. 2013). In addition, AmB has several side effects because of formation of aqueous pores (Cohen 1998); among these, nephrotoxicity (Fanos and Cataldi 2001) and hematotoxicity (Wong-Beringer et al. 1998) are the most serious.

The AmB molecule comprises a macrolactone ring, which is $\beta$-glycosylated at position $\mathrm{C} 19$ with a mycosamine group (Ganis et al. 1971; Jarzembska et al. 2012). The ring is an almost flat chromophore with seven conjugated double bonds in the trans conformation. The ring also contains a more flexible polyol subunit (Fig. 1). At positions $\mathrm{C} 13$ and $\mathrm{C} 17$, the macrolactone ring contains a hemiketal ring. The presence of a carboxyl group at C16 and an amino group in the mycosamine head group determines the amphoteric character of this molecule. In addition, the specific AmB three-dimensional structure which has well defined hydrophobic and hydrophilic regions is responsible for its amphipathic properties. Consequently, AmB is poorly soluble in highly polar and apolar solvents. For this reason, AmB tends to aggregate (Shervani et al. 1996) in highly polar solvents, for example water, which gives rise to a variety of models explaining its antifungal activity.

Several possible mechanisms of action of AmB can be found in the literature. The first, oldest, and most studied is the ion-channel model proposed by Finkelstein and Holz 
Fig. 1 Schematic representation of sterols and amphotericin B

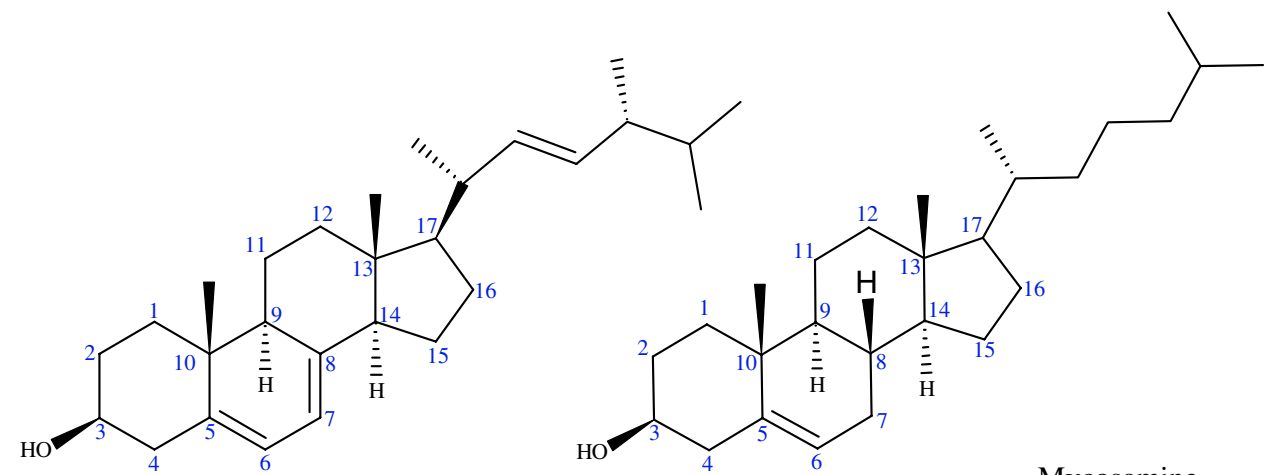

Mycosamine

Ergosterol

Cholesterol

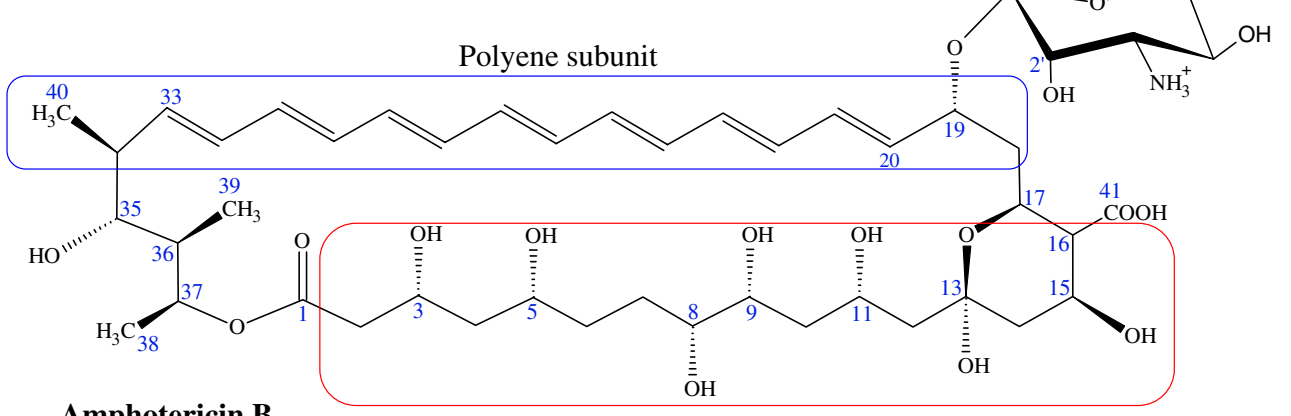

Polyol subunit

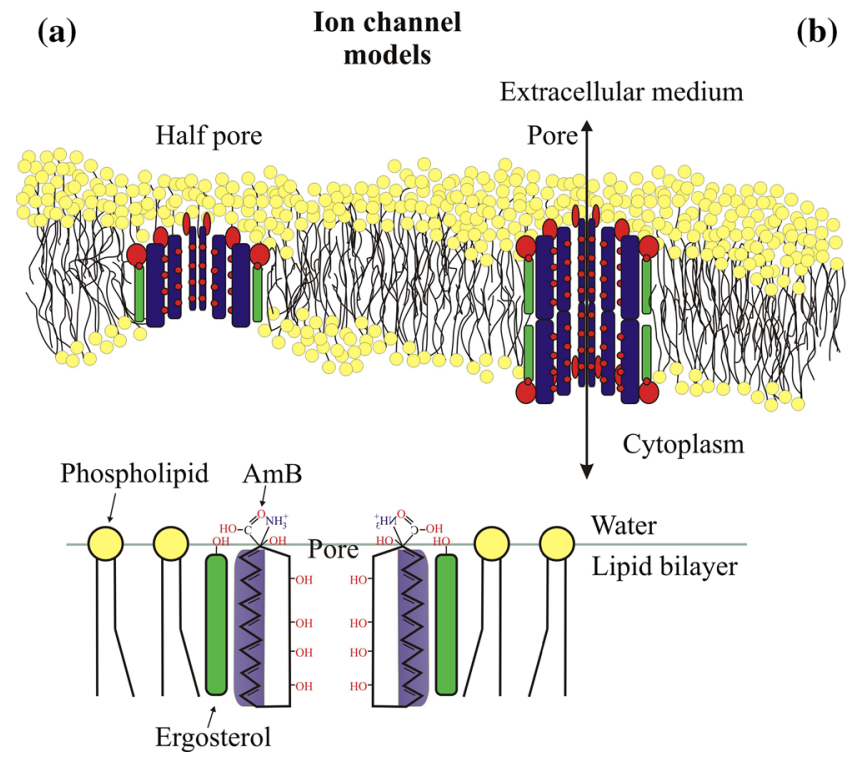

(b)

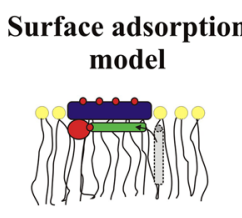

(c) Sterol sponge model
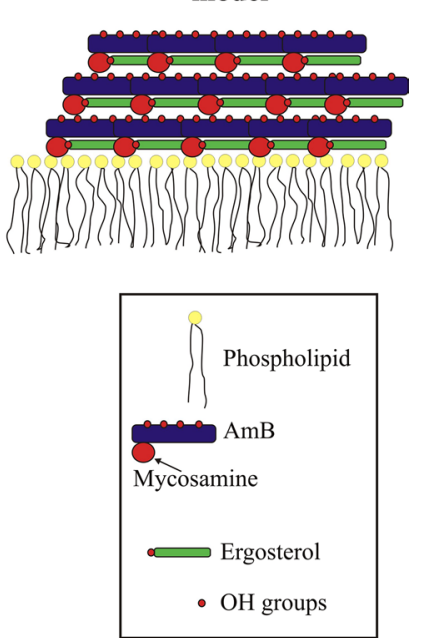

Fig. 2 Models of amphotericin B function in phospholipid bilayers. a Classical-ion channel model in which $\mathrm{AmB}$ molecules aggregate in such a way that they form a barrel with their polyhydroxy chain groups pointing inward and their heptaene parts pointing outward. b Surface adsorption model in which AmB extracts ergosterol from the bilayer to the surface. c Sponge model in which large AmB aggregates extract ergosterol from the phospholipid membrane

be formed which bond two sides of the bilayer (Fig. 2a). The pore can be formed from different numbers of monomers, ranging from 4 to 12 (Cass et al. 1970; Gruszecki et al. 2003), and this has been confirmed by channel-conductivity experiments (Brutyan and McPhie 1996; Cotero 
et al. 1998). These pores are responsible for leaking of $\mathrm{K}^{+}$ions and small organic particles vital for cell function. The second concept is based on the oxidative cell damage caused by amphotericin B (Brajtburg et al. 1985; SokolAnderson et al. 1988), which affects fungi and causes lysis of red cells. This effect induces formation of reactive oxygen species, for example superoxide, hydrogen peroxide, and hydroxyl radicals, which oxidize the lipid membrane (Lamy-Freund et al. 1985). AmB can bond to low-density lipoprotein receptors and probably modify their structure by oxidation (Barwicz et al. 1998, 2000). The oxidation damage induced by AmB can affect other cell functions not related to changes in cell permeability (Sokol-Anderson et al. 1986; 1988). AmB can also mediate killing of fungi cells by induction of a strong intracellular oxidative burst, as is observed for Cryptococus neoformans, which can be responsible for protein carbonylation (Sangalli-Leite et al. 2011). The third model is based on AmB surface adsorption in which antibiotic molecules oriented parallel to the plane lipid surface destabilize the membrane by sequestering ergosterol to the bilayer surface (Fig. 2b) (de Kruijff and Demel 1974; Mouri et al. 2008). The last concept is the sterol sponge model in which AmB exists as a large aggregate in the proximity of the fungal membranes which extract ergosterol from it (Anderson et al. 2014). In this process, strong interaction between ergosterol and AmB is a crucial (Palacios et al. 2011; Gray et al. 2012).

To better understand the interactions between $\mathrm{AmB}$ and living cells, it is important to understand how AmB interacts with lipids, including the arrangement of $\mathrm{AmB}$ in lipid-sterol environments (Matsumori et al. 2006; Gagoś and Arczewska 2010), the function of fungal cell walls, and the effects of AmB aggregation in biological systems (Barwicz et al. 1992; Barwicz and Tancrede 1997). Only a full understanding of these phenomena can lead to the design of forms of AmB with lower toxicity and greater efficacy (Bolard et al. 1980b; Bolard and Cheron 1982; Paquet et al. 2002; Matsuoka and Murata 2003; Sternal et al. 2004; Gabrielska et al. 2006; Hac-Wydro and Dynarowicz-Łątka 2006; Foglia et al. 2011), not only by appropriate formulation (Brogden et al. 1998; Andres et al. 2001; Hac-Wydro et al. 2005c; Menez et al. 2006; Moen et al. 2009; Hamill 2013; Pham et al. 2013) but also by molecular modification (Hac-Wydro et al. 2005c; Paquet and Carreira 2006; Czub et al. 2009; Croatt and Carreira 2011; Tevyashova et al. 2013; Wilcock et al. 2012, 2013). For instance, toxicity can be reduced by using appropriate cationic derivatives of AmB (Slisz et al. 2004). Other AmB modifications reveal that $-\mathrm{OH}$ groups in positions $\mathrm{C} 8$ and $\mathrm{C} 9$ or positions $\mathrm{C} 7$ and $\mathrm{C} 10$ give the most active forms of $\mathrm{AmB}$, whereas forms with $-\mathrm{OH}$ groups at the $\mathrm{C} 7$ and $\mathrm{C} 9$ positions (Fig. 1) had less antifungal activity (Tevyashova et al. 2013). Applying modifications to one of the many - $\mathrm{OH}$ groups in

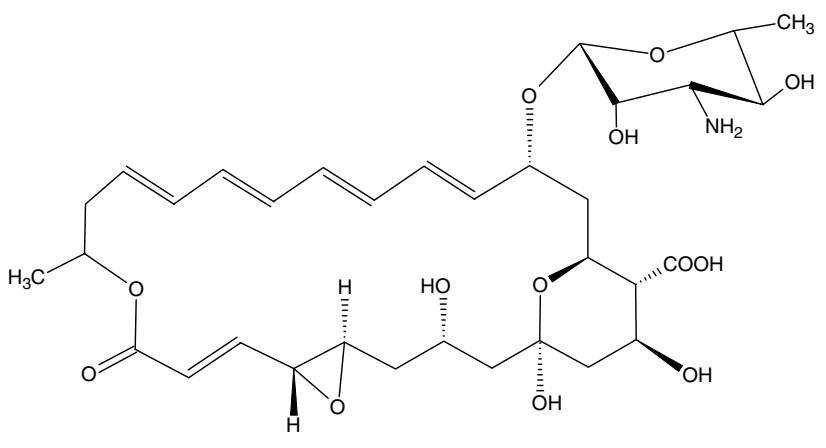

Fig. 3 Structure of natamicin, another antifungal polyene antibiotic which is unable to create pores through cell membranes (is too short) but binds ergosterol in a similar manner to AmB

AmB can affect ion transport through ion channels (Wilcock et al. 2012). Fluorescein-AmB conjugates can be a powerful tool for observing biological processes in living cells (Zumbuehl et al. 2004a), and tryptophan-AmB conjugates can increase channel activity in the absence of sterols (Zumbuehl et al. 2009). Recently synthesized AmB derivatives, and their antifungal properties and toxicity are widely described elsewhere (Baginski et al. 2006; Slisz et al. 2007; Baginski and Czub 2009).

Because of the substantial number of publications on medical formulations and clinical applications of AmB, this review concentrates on the most important discoveries related to the above mentioned questions reported in the literature of the last decade.

\section{AmB sterol binding}

The generally accepted mechanism of action of $A m B$ is based on the effects of both ergosterol binding and pore formation. According to Yilma et al. (2007), Palacios et al. (2011), and Gray et al. (2012), sterol binding is necessary for antifungal activity and AmB channel formation is only one of several sterol-binding-dependent mechanisms of action. For example, the antifungal compound natamycin (Fig. 3), which is shorter in length than AmB, was recently reported to bind ergosterol in yeast cell membranes without pore formation (te Welscher et al. 2008). This effect, inter alia, led the Burke group to the conclusion that the main factors responsible for $\mathrm{AmB}$ antifungal activity must be related not to pore formation but rather to binding of ergosterol (Gray et al. 2012). This concept was extended in the next work of this group (Anderson et al. 2014). According to authors, extramembranous AmB aggregates work as sponges extracting ergosterol from the fungal membranes (Fig. 2c). This is, overall, a coherent mechanism which agrees with biological observations of large AmB aggregates or AmB-rich structures (Strachecka et al. 2012). However, in both sets of experiments 
Fig. 4 Structures of amphidinol-3 and 6-F-ergosterol. This modification inhibits interactions with $\mathrm{AmB}$ but not with another polyene antibiotic, amphodinol-3

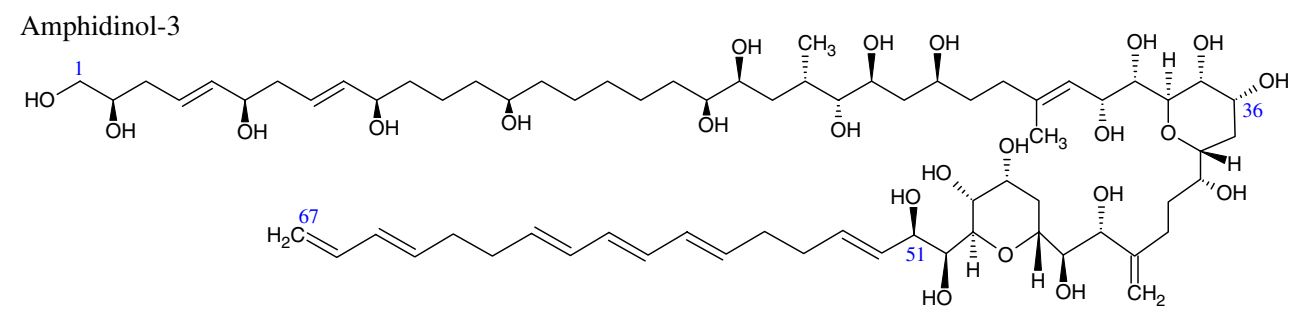

6-F-ergosterol the ergosterol-to-lipid ratios, i.e. 1:10 (Gray et al. 2012) and 1:40 (Anderson et al. 2014), are significantly lower than those observed in natural systems; in S. cerevisiae, for example, this ratio is 30:70 (Schneiter et al. 1999). Alteration of the sterol-to-phospholipid ratio in fungal cell membranes is an established mechanism in the development of AmB resistance (O'Shaughnessy et al. 2009). As a result, it is vital to use a sterol-to-phospholipid ratio that models that found in AmB-sensitive fungal membranes rather than a ratio that suits the experimental technique used. In mammals, moreover, cholesterol is available in large amounts; such sponges can therefore be saturated with cholesterol much earlier than those in contact with fungal cell walls. It can easily be calculated thermodynamically that the $\mathrm{AmB}$-cholesterol/AmB-ergosterol balance in situations in which cholesterol is in excess will be shifted to the advantage of AmB-cholesterol; thus, ergosterol extraction will be greatly limited. Moreover, living fungi have cell walls constructed of chitin, which is hydrophilic. This is a serious kinetic barrier to transport of ergosterol through fungal cell walls to the AmB super aggregates. The pore model is free from such effects and thus seems an attractive proposition.

Molecular dynamics simulations confirm that in the membrane environment $\mathrm{AmB}$ interacts with ergosterol 3-4 times more strongly than in solution, and this could be responsible for the more effective AmB assembly leading to functional transmembrane channels (Neumann et al. 2009, 2010, 2013a). In the first of these references the system consists of AmB-sterol complexes embedded in a sterol-DMPC system with a sterol content of $25 \%$. In the second reference the system is a DMPC bilayer with a sterol content of $30 \%$ and in the last reference DPMC containing 0 and $30 \%$ sterol is studied. The last study shows that AmB-cholesterol bonding is weaker not only because of weaker van der Waals (vdW) interactions compared with ergosterol, but also because of entropy reduction associated with a decrease in the conformational flexibility of the sterol side-chain. The significant effect of vdW interactions was confirmed by introducing a fluorine atom at the C6 position in ergosterol (Kasai et al. 2011). The fluorine weakens the sterol interaction with $\mathrm{AmB}$, which is not observed for another antifungal antibiotic, amphodinol-3 (Fig. 4). The weaker interaction between AmB and cholesterol compared with that between AmB and ergosterol leads to the different behavior of this antibiotic in monolayers containing these sterols (Saint-Pierre-Chazalet et al. 1988; Seoane et al. 1998, 1999a, b; Miñones et al. 2005; Chang et al. 2010). These differences are also observed for modified AmB molecules (Hac-Wydro et al. 2005a, b, c; Baginski et al. 2006).

\section{Effect of the mycosamine group}

It is known that the mycosamine group in AmB is important in the sterol-binding process, as is confirmed by isothermal titration calorimetry (Wilcock et al. 2013). If the group is removed, AmB binds neither ergosterol nor cholesterol and loses its antifungal properties. On the basis of the studies mentioned above and the fact that mycosamine has only been found in polyene macrolide natural products, this polyene-glycoside linkage serves as a sterol-binding group. Interestingly, the glycoside subunit is very similar to the main component of the cell walls of fungal chitin (Ramanandraibe et al. 1998), which is not observed in mammals. The $\mathrm{C}^{\prime}-\mathrm{OH}$ from the mycosamine subunit is of major importance in the binding of $\mathrm{AmB}$ to the $3 \beta$ hydroxyl group of cholesterol and ergosterol (Matsumori et al. 2005) (Fig. 1). However, when the $\mathrm{OH}$ group bonded to $\mathrm{C}^{\prime}$ from mycosamine (Fig. 1) is removed, cholesterol binding is substantially weaker whereas the ergosterol-AmB bond is still strong (Wilcock et al. 2013). These different bonding strengths are explained by authors on the basis of the different conformer types for deOAmB-ergosterol and deO$\mathrm{AmB}$-cholesterol which results in weaker vdW interactions 
for deOAmB-cholesterol. The stronger AmB-ergosterol interaction compared with that with cholesterol is attributed to the double bond and the additional methyl group in this sterol (Vertutcroquin et al. 1983; Charbonneau et al. 2001; Baginski et al. 2002). This specific atomic pattern is responsible for the better matching of ergosterol to the AmB heptaene chain (Baran et al. 2009).

\section{Effect of ergosterol concentration}

A recent study has shown that the antifungal mechanism is based mostly on AmB binding to ergosterol which affects vital cellular functions in yeast-like endocytosis, vacuole fusion, pheromone signaling, and control of the activity of membrane proteins, among others (Gray et al. 2012; Palacios et al. 2011). However, no correlation has been observed between the level of ergosterol in different clinical yeast isolates and the antifungal activity of AmB (Gomez-Lopez et al. 2011) which is in contrast with results obtained for artificial membranes, for which maximum AmB activity was observed for $10 \mathrm{~mol} \%$ ergosterol (Teerlink et al. 1980) and for which an increase in the amount of ergosterol in the monolayer promoted AmB incorporation (Barwicz and Tancrede 1997). The lack of correlation between the level of ergosterol in cell membranes and $\mathrm{AmB}$ antifungal activity can be related to different mechanisms of resistance of living yeasts (Sanglard and Odds 2002), different sterol compositions (Seitz et al. 1979; Brun et al. 2004; Vandeputte et al. 2008, 2011), greater membrane fluidity (Younsi et al. 2000; Venegas et al. 2003), and, most probably, the effect of cell walls (Ramanandraibe et al. 1998). This shows that artificial membranes are only an approximation of natural ones and results from such systems should be compared with those from natural ones with care.

\section{AmB aggregation}

Even if the pore formation by AmB through the bilayer is of secondary importance, it is still an important aspect of its antifungal activity. Because aggregation of AmB in the lipid matrix is a crucial step in the barrel-stave channel formation, it is crucial to fully understand this process. A substantial number of experiments have been conducted with use of a wide range of techniques.

Hargreves et al. investigated the effect of aggregation of AmB in phospholipid nanodiscs (ND). They found that at a concentration of $2.5 \mathrm{mg}$ AmB per $10 \mathrm{mg}$ phospholipid AmB occurs in self-associated forms, but below this concentration the AmB occurs as the monomeric form observed in solvents (Hargreaves et al. 2006). This is in accordance with a previous study in which aggregated forms of AmB were observed when the ratio of AmB to lipid molecules was higher than 1:1,000 (Fujii et al. 1997). Below this concentration, AmB exists in the lipid bilayer mostly in the monomeric form. Gruszecki et al. (2009) showed that AmB forms aggregated as dimers in pure lipid bilayers and lipid bilayers containing cholesterol, whereas in bilayers containing ergosterol both monomeric and aggregated forms are present. This dynamic molecular study also confirmed that AmB forms dimers in lipid bilayers with and without sterols, but in the presence of ergosterol AmB-AmB interaction is less favorable (Neumann et al. 2013a). This was also confirmed by fluorescence lifetime imaging microscopy of monomolecular layers formed at the argon-water interface deposited on to a glass support by the LangmuirBlodgett technique. In this situation only monomeric forms of AmB were observed for monolayers containing ergosterol (Gruszecki et al. 2009). Comparison between FTIR and Raman spectra obtained for crystalline and amorphous $\mathrm{AmB}$ reveals that in lipid environments $\mathrm{AmB}$ aggregates and/or dimers have a similar arrangement to that observed in mono crystals, which is characterized by a $\sim 1,010 \mathrm{~cm}^{-1}$ band (Gagoś et al. 2012). For amorphous AmB obtained by DMSO evaporation, in which AmB molecules are randomly oriented, this band is not observed. The presence of the aggregated forms in DMPC bilayers containing ergosterol is also confirmed by solid-state NMR (Matsumori et al. 2006). The greater number of AmB monomers is related to the stronger interaction of $\mathrm{AmB}$ with ergosterol, which is responsible for AmB monomerization. Circular dichroism (CD) experiments reveal that $\mathrm{AmB}$ can already associate in water solutions in the range $5 \times 10^{-7}-10^{-4} \mathrm{M}$ (Mazerski et al. 1982). The AmB aggregation process also occurs in monocomponent monolayers formed at the argon-water interface. Under these conditions spontaneously formed dimers with homogeneous distribution are observed in the monolayer. These dimers can assemble as higher oligomers which are most probably responsible for channel formation (Gagoś and Gruszecki 2008). Brewster angle microscopy has shown that at low surface pressure the surface area of $\mathrm{AmB}$ in the expanded state $(0.4 \mathrm{mN} / \mathrm{m})$ is $\sim 180 \AA^{2}$, which corresponds to horizontal AmB molecules. In the condensed state, the surface area is $55 \AA^{2}$, which corresponds to vertically oriented AmB molecules. Transition from one orientation to the other is continuous at plateau surface pressure (Minones et al. 2001). AmB molecules on a water surface are most probably in the aggregated form. Diezi and Kwon (2012) measured the process of aggregation of AmB in 1,2-distearoyl-sn-glycero-3-phosphoethanolamine- $N$-(methoxy(poly(ethylene glycol))-5000 (ammonium salt) (PEG-DSPE) micelles. They found that AmB in the presence of ergosterol is aggregated whereas in the presence of cholesterol or pure PEG-DSPE it is mostly in the monomeric form. This seems contrary to results presented earlier. However, this system differs substantially from that described above and AmB aggregation can occur 


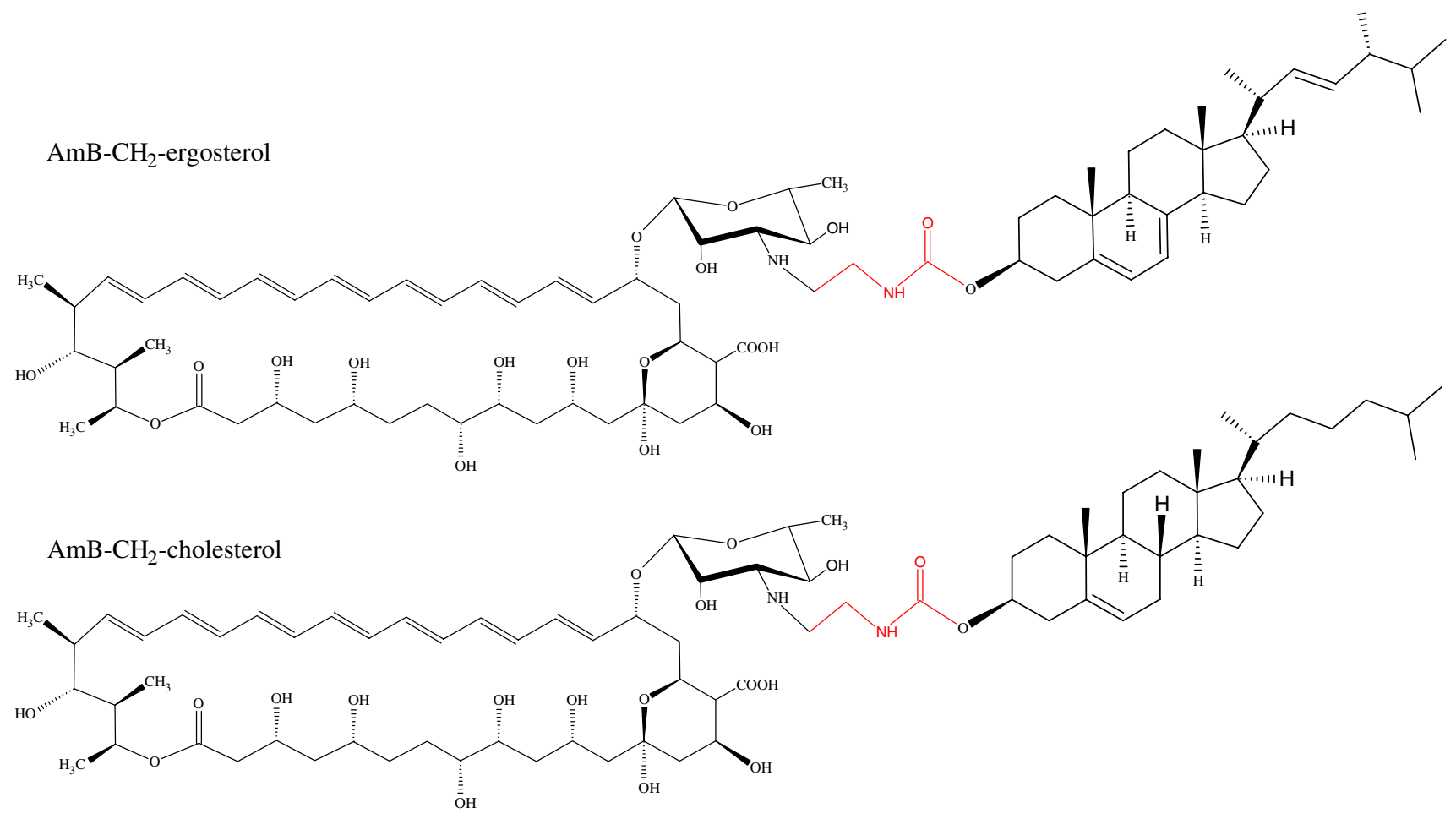

Fig. 5 Structures of AmB-sterol linking. In this case, only the link built of two carbon atoms is shown; in the original study a link containing 6 carbon atoms was also studied

differently. In this case, the amphiphilic character of $\mathrm{AmB}$ could be of crucial importance in interactions with these specific environments (PEG polymer), which can, in turn, change the aggregation behavior of AmB.

In work by Gruszecki et al. (2012) fluorescence techniques were used to detect dimers and aggregates of AmB in different environments. However, according to studies by Bolard et al. $(2009,2011)$ those bands should not be related to dimers and/or aggregates of AmB. A recent study has shown that characteristic changes of electronic absorption spectra previously related to formation of $\mathrm{AmB}$ dimer and/or oligomer aggregates exactly overlap bands related to the oxidized forms of AmB (Gagoś and Czernel 2014). The appearance of oxidized AmB forms in systems measured in air is not surprising, because Ganis et al. (1971) had already noted that $\mathrm{AmB}$ is sensitive to oxidation. Therefore, atmospheric oxygen may be sufficient to oxidize double bonds in AmB molecules in the presence of light. This simply suggests that several spectroscopic experiments in which the AmB was not appropriately protected against oxidation should be repeated or at least reinterpreted.

\section{$\mathrm{AmB}$ pore formation}

Yang et al. (2013) measured the effect of AmB on pore formation in membranes containing ergosterol by use of fluorescent dyes of known average diameter. They showed that increasing $\mathrm{AmB}$ concentration tends to increase the preferential accumulation of $\mathrm{AmB}$ ion channels in membranes. It has also been found that membrane pores can be formed not only in the presence of sterols but also without them (Cotero et al. 1998). It is important to mention that channel formation depends on $\mathrm{AmB}$ concentration, and the presence of sterols is not necessary for this process (Fujii et al. 1997). Addition of sterols also affects the dwell time of artificial AmB channels in the patch-clamp technique, which is longer for cholesterol-containing membranes (ions occupy channels for a longer time, thus blocking them) than for ergosterol-containing membranes (Matsuoka and Murata 2002). For that reason, ion transport through channels created in the presence of ergosterol is more efficient than that in the presence of cholesterol (Ostroumova et al. 2012). The authors suggested that the process of association and/ or dissociation of channel-forming molecules depends on membrane fluidity. This is in agreement with previous studies in which sterols did not directly affect pore formation but rather affect the membrane structure which produces a different threshold for the formation of $\mathrm{AmB}$ channels (Cotero et al. 1998). Results similar to those of Matsuoka and Murata (2002) have been obtained for sterols linked covalently to AmB (Fig. 5). In this case, the probability of the channel being open was greater for ergosterol-linked 
AmB than for cholesterol-linked AmB (Matsumori et al. 2004). This can be explained on the basis of results from a study of neutron diffraction of multibilayers (Foglia et al. 2012) (sterol-lipid ratio 30:70), which revealed formation of full $\mathrm{AmB}$ pores in the lipid bilayer. Detailed modeling shows that cholesterol and AmB in AmB-POPC-cholesterol bilayers are wholly contained within the separate leaflets of the bilayers. For AmB-POPC-ergosterol, both $\mathrm{AmB}$ and ergosterol intrude from one leaflet to the opposite one. Such connectivity between half-pores can stabilize the transmembrane ion-channel structure and thus increase its permeability. Interestingly, insertion of AmB in the POPCcholesterol bilayer causes a $3-\AA$ shift in the position of cholesterol, whereas for POPC-ergosterol the shift is only 0.5 $\AA$. Because this is only the scattered length density profile of all the atoms in the system, this might indicate reorientation of the mycosamine group in the bilayer, as has been suggested by the authors and additionally by work of Matsumori et al. (2005). Similar to the neutron data, surface $\mathrm{X}$-ray scattering data also indicate vertical insertion of $\mathrm{AmB}$ into the lipid monolayer (Kamiński et al. 2014). It should be noted that the article by Gagoś et al. (cited in Foglia et al. 2012) relates to the DPPC not POPC lipid system. In general, the effect of AmB and nystatin on ion permeability is much stronger when lipid membranes contain ergosterol. Permeable ion-channels are also formed in the presence of cholesterol, as was investigated by Yilma et al. (2007) for a cholesterol monolayer. Similar to Sykora et al. (2004) and, they found that $\mathrm{AmB}$ and cholesterol form a complex with of stoichiometry 2:1, but Yilma et al. also showed that $\mathrm{AmB}$ in the presence of cholesterol assembles in three, four, etc., subunit aggregates which form ion channels. According to the above-mentioned studies, it is most probable that the AmB-cholesterol interaction is the main factor responsible for toxicity to mammalian cells whereas the interaction between $\mathrm{AmB}$ derivatives and lipids is less important for toxicity.

Formation of cation-selective ion channels by $\mathrm{AmB}$ in a model lipid membrane and in membranes of eukaryotic cells is reviewed in detail by Cohen (2010). This review also concentrates on the effect of membrane thickness, the types of sterol used, and the sterol-rich lipid rafts on the pore-formation process, and led the author to develop a cell model that serves as a framework for understanding the intracellular $\mathrm{K}^{+}$and $\mathrm{Na}^{+}$concentration changes induced by the cation-selective AmB channels. Ion-channel selectivity has also been observed for new conjugates bearing a calixarene structure covalently linked to four AmB molecules (Paquet et al. 2006). These macro molecules adopt a cone conformation that mimics the structure of membrane pores. These artificial pores have similar properties to those created naturally by $\mathrm{AmB}$ in membranes, which strongly supports the generally accepted classical AmB pore model.
AmB channel diameter

Interestingly, the channels created by $\mathrm{AmB}$ in erythrocyte membranes (with cholesterol) are in the range 0.36$0.37 \mathrm{~nm}$ as measured in a conduction osmotic protected experiment (Katsu et al. 2008). The channel diameters measured by Katsu et al. (2007) for liposomes composed of egg phosphatidylcholine and cholesterol in a conduction osmotic protected experiment are also in a similar range, $0.36-0.46 \mathrm{~nm}$. For ergosterol-rich membranes the diameter is in the range 0.4-1.0 nm (Reeves et al. 2004). This indicates that the sterols do not significantly affect channel diameter and thus the subtle effect of better conductance must be related to sterol distribution in the proximity of the AmB molecules (Neumann et al. 2013b), which affect the electric field inside the channel and consequently the dwell time, as already mentioned. The measured diameters are similar to that measured earlier by atomic force microscopy (AFM) ( 0.6 nm) (Gruszecki et al. 2002, 2003). In this case, AFM should show the upper limit of pore diameter, whereas osmotic techniques underestimate pore size because of intermolecular interactions. By use of different fluorescence dyes, Yang et al. (2013) demonstrated that in ergosterol-rich membranes (bilayers) the pore size (diameter) depends on $\mathrm{AmB}$ concentration. At low $\mathrm{AmB}$ concentrations $(50 \mathrm{pg} / \mathrm{ml})$ this is approximately $0.16 \mathrm{~nm}$ whereas for AmB concentrations of $2 \mathrm{ng} / \mathrm{ml}$ the pore diameter is nearly $16 \mathrm{~nm}$. From this experiment it is clear that the concentration of $\mathrm{AmB}$ in bilayers is of primary importance in determining pore size, whereas sterols have a minor effect only. The distance between AmB dimers in the barrel-stave ion channel corresponds to the distance between covalent dimers of AmB, which is $6.9 \AA$, measured for multilamellar vesicles by use of solid-state NMR (Umegawa et al. 2012a). This distance is significantly shorter than that previously measured by the same group, i.e. $11-12 \AA$ (Kasai et al. 2008). According to the authors, this difference results either from covalent linkage, as a result of which AME (two linked AmB molecules) units are closer in the membrane assembly, or from inappropriate assumptions when estimating the intermolecular $13 \mathrm{C}-19 \mathrm{~F}$ distance.

\section{Geometry of AmB-sterol associates}

Molecular dynamics simulations in water environments suggest that AmB forms AmB-ergosterol-AmB (2:1 stoichiometry) associates with head-to-head interaction between AmB and ergosterol (Baran et al. 2009). The calculated stability of this complex was substantially higher than that of 1:1 stoichiometry. The energy of the complex is highly dependent on the surrounding environment, and for water the head-to-head conformation is preferable. As might be expected, AmB-ergosterol complexes can behave 
differently in a lipid bilayer part of which is hydrophobic. A solid-state NMR study of multilamellar vesicles conducted by Umegawa et al. $(2008,2012 b)$ suggests that both head-to-tail and head-to-head conformations are possible (Fig. 6; POPC-sterol vesicles containing $10 \%$ sterol). The head-to-tail conformation of $\mathrm{AmB}$-ergosterol requires that the AmB dimer is also in the head-to-tail conformation and thus the orientation of ergosterol relative to both AmB molecules should be the opposite. In vivo, AmB is delivered from outside the cell only, and the most reasonable way of entering the membrane is by embedding the less polar part of AmB (i.e. the tail) into the lipid environment from water. The head-to-tail conformation is much less preferable. Another explanation is to form an AmB-ergosterolAmB complex in the head-to-tail conformation compared with $\mathrm{AmB}-\mathrm{AmB}$ molecules by diffusion of the binary complex of AmB-ergosterol up and down in the membrane. If another single AmB molecule can move from one lipid leaflet to another (without flip-flop), then sterols from this second leaflet can interact with AmB in a head-to-tail manner. A similar result can be achieved when a binary AmBergosterol complex moves from one leaflet to another without flip-flop and meets a single $\mathrm{AmB}$ molecule in the right conformation. However, in this case also, floating from one lipid leaflet to another is very likely. The idea that AmB-AmB head-to-tail structures can be formed in membranes-especially in vivo-should therefore be accepted with caution.

Interestingly, quantum chemical calculations predict that the head-to-tail AmB dimer conformation has the lowest energy, but this is solely for isolated systems without any effect of solvent (Jarzembska et al. 2012). A similar conformation was also observed by Barwicz et al. (1993) in AmB aqueous solution. They recorded bathochromic and hypsochromic shifts in spectra which are associated with "card pack" and "head-to-tail" AmB patterns. The latter was interpreted by authors as an effect of dimerization along the longest molecular axis of $\mathrm{AmB}$, whereas the former is the effect of interactions between molecules responsible for hydrophobic pore formation. These results are apparently in contrast with the molecular dynamics study from the bilayer where head-to-head should be dominant (Neumann et al. 2013b) (DMPC bilayer with $30 \%$ sterols). These differences can be simply explained as the effect of different environments. AmB, as an amphiphilic molecule, can form, or even should form, totally reverse associates or structures in non-polar (lipids acyl chains) versus polar (water) environments. The lack of any environment in quantum chemical calculations can substantially affect the total energy of dimers of this size and thus lead to mistaken conclusions. Other experimental studies suggest that both forms of AmB-head-to-tail and head-to-head (tail-to-tail)—occur naturally in a lipid environment when the concentration is high enough to enable this process (Volmer and Carreira 2010; Hirano et al. 2011).

Interaction of $\mathrm{AmB}$ with lipids

It is obvious that phospholipids are always associated with sterols in biological membranes; therefore, when analyzing sterol-AmB interactions, the effect of the lipids must also be taken into account (Bolard 1986a, b; Rapp et al. 1997; Dynarowicz-Łątka et al. 2003; Hac-Wydro and Dynarowicz-Łạtka 2006). Usually, the interaction leads to the formation of AmB complexes, as for dipalmitoyl phosphatidylserine (DPPS), for which the stoichiometry between AmB and DPPS is 2:1 (Minones et al. 2003). The optimum stoichiometry for an the AmB-DPPC system is also 2:1, with two horizontally oriented $\mathrm{AmB}$ molecules and one DPPC molecule in a vertical position, as proposed by Minones et al. (2002). The interaction between AmB and phospholipids on formation of ion channels across a biomembrane was investigated by Matsuoka et al. (2003), by using their covalent conjugates. As might be expected, the membrane-permeabilizing activity was substantially affected by the chain lengths of the fatty acyl groups of the phospholipids. Acyl chain length has a direct effect on bilayer thickness; it can also affect the lipid-AmB interaction and, as a consequence, ion channel assembly. The different interaction of AmB with lipid membranes in vesicles was also observed for the $(S)$ and $(R)$ enantiomers of POPC (Jeon and Carreira 2010). The kind of lipid used and its fluidity have a substantial effect on pore formation (Ostroumova et al. 2012). It has also been found that AmB interacts differently with egg yolk phosphatidylcholine, dimyristoyl (DMPC), and dipalmitoyl phosphatidylcholine (DPPC) phospholipid bilayers (Bolard et al. 1980a, b). The double bond of egg yolk phosphatidylcholine affects lipid fluidity, which has a direct effect on AmB pore formation in bilayers. It was also found that AmB can occur in different aggregation forms in lipid bilayers. Marty and Finkelstein (1975) suggested that AmB can form pores and half pores, that sterols play a minor role, and that pore formation is prevented by some lipids.

The different lengths of phosphatidylcholine saturated acyl chains (ranging from 14 to 22 carbon atoms) and the presence of cholesterol affect the conformation of $\mathrm{AmB}$ in bilayer vesicles (Bolard and Cheron 1982). For POPC vesicles containing sterols, bilayer thickness was affected not only by the kind of lipid used but also by the concentration of AmB. Ions can also affect the AmB-lipid interaction. Arczewska and Gagoś (2011) found that AmB has a greater affinity for DPPC in the presence of $\mathrm{K}^{+}$than in the presence of $\mathrm{Na}^{+}$. The most stable monolayers in the presence of both ions were formed by AmB and DPPC with 1:1 and 2:1 stoichiometry. The FTIR spectra revealed that 
(a)

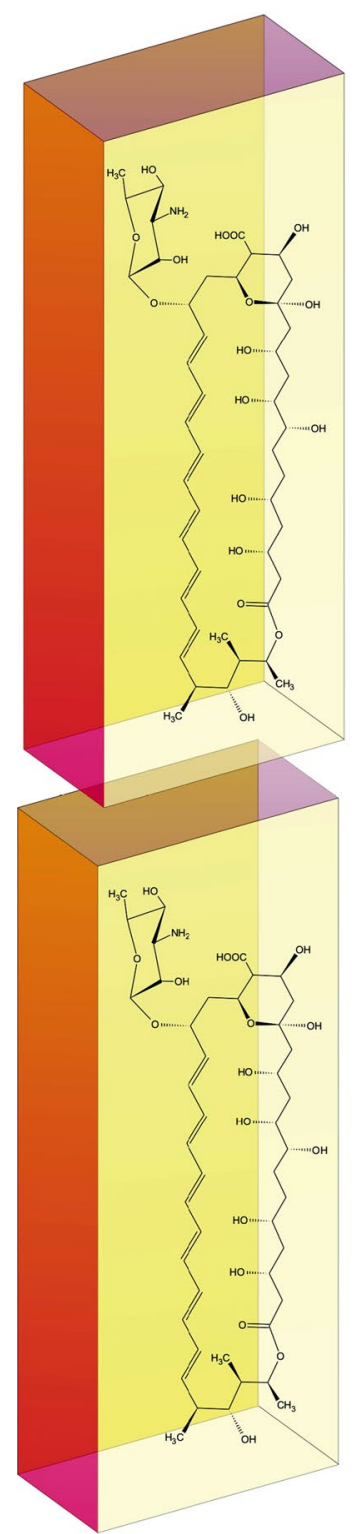

(b)

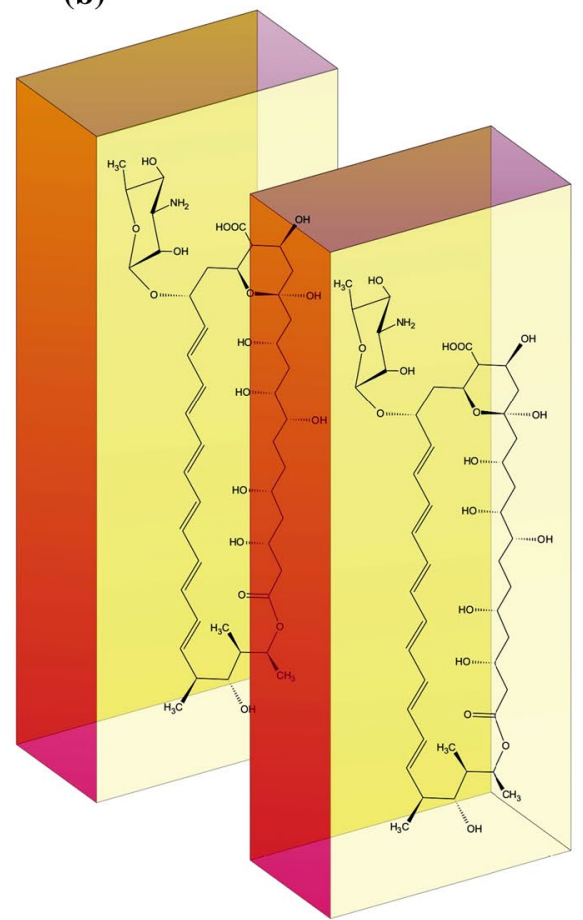

(c)

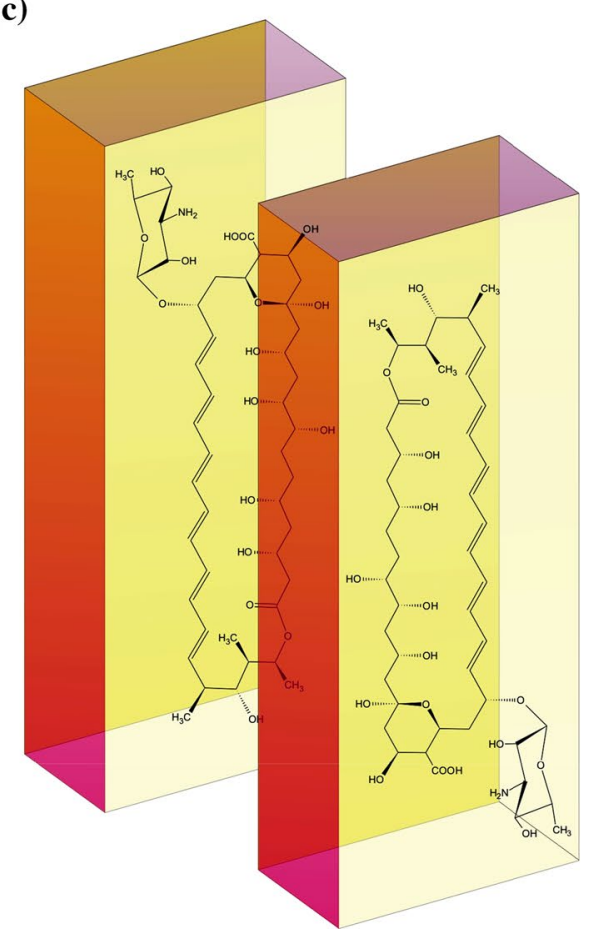

(d)

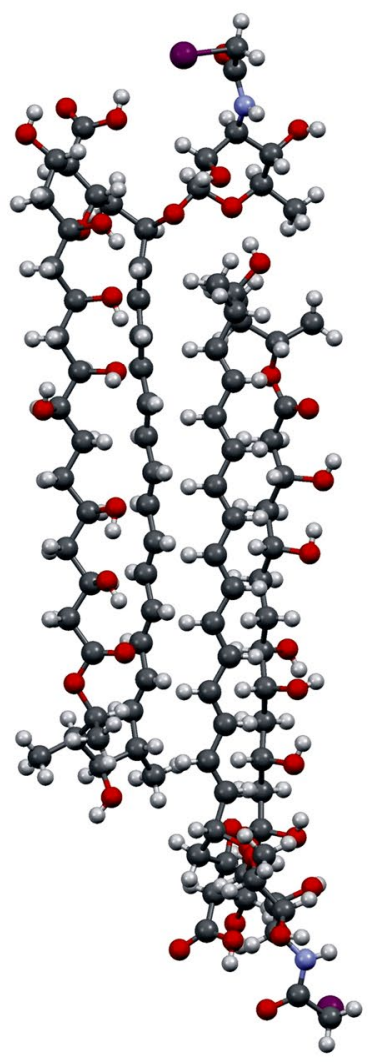

(e)

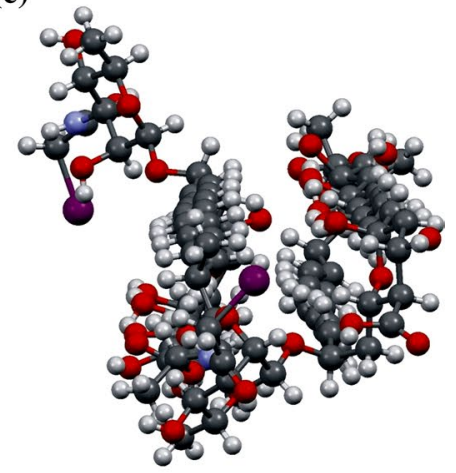

Fig. 6 a Card-pack, b head-to-head, and $\mathbf{c}$ head-to-tail orientation of AmB molecules in a dimer. d Iodoacetyl AmB (AmB-I) molecules packed into a crystal lattice [11]. e Side view of the same structure.

the ionic state of $\mathrm{AmB}$ (which is a function of $\mathrm{pH}$ ) and the presence of sterols led to changes in membrane fluidity and the molecular packing of the AmB molecules in the lipid
It can be seen that AmB-I molecules have head-to-tail orientation and the polyol subunit is in contact with the heptaene chain

membranes (Gagoś and Arczewska 2012). In this way, $\mathrm{pH}$ can affect not only AmB but also liposomes. According to these authors, both $\mathrm{pH}$ and the presence of sterols affect 
pore formation. Thus, it is important to conduct such experiments at physiological $\mathrm{pH}$.

\section{Orientation of $\mathrm{AmB}$ in membranes}

Electron spin resonance spectroscopy revealed that AmB orientation in lipid model membranes is a two-step process (Man and Olchawa 2013). At a concentration of 0.25$0.5 \%$ AmB molecules initially lie flat; at higher concentrations, ca. $2.5-3 \%$, in a monolayer re-orientation to the vertical position occurs. This vertical orientation of AmB is responsible for channel formation and bilayer perforation. In this orientation $\mathrm{AmB}$ interacts strongly with the lipid head groups and restricts the molecular motion of choline (Gabrielska et al. 2006). Fourier-transform infrared spectroscopic (FTIR) study of deposited lipid (free and with sterols) monolayers after binding $\mathrm{AmB}$ from the water subphase revealed that most of the $\mathrm{AmB}$ molecules bound to the membrane were located in the polar head groups or interacted with them. In pure DPPC and DPPC containing cholesterol, the distribution between vertically and horizontally oriented AmBs is similar. However, in the presence of ergosterol the dominant form of AmB is horizontal (Gagoś et al. 2005). The possibility cannot be excluded that the transition of the monolayer on the solid substrate had an effect on the position and orientation of $\mathrm{AmB}$, but a strong interaction between $\mathrm{AmB}$ and ergosterol was still observed. It is also possible that the more rigid layers containing ergosterol were less accessible to $\mathrm{AmB}$, which, therefore, accumulated under the monolayer parallel to the surface and after transfer to the solid substrate was between the substrate and polar head groups of the lipid. Even more surprising results were obtained from a molecular dynamics study in which AmB preferentially took a vertical position, perpendicular to the membrane surface of dimyristoyl phosphatidylcholine (DMPC), with no propensity to enter the membrane (Sternal et al. 2004). The system on which the calculation was performed consisted of 200 molecules of DMPC, one molecule of AmB and 8,065 water molecules. At initialization, $\mathrm{AmB}$ was placed on the bilayer surface. According to the modeling, it is very likely that a single molecule enters the membrane, which suggests that $\mathrm{AmB}$ has to be at least in the dimeric form to enter the bilayer. The latest X-ray gaswater interface diffraction studies performed for DPPC monolayers show that AmB is incorporated into a monolayer, perpendicular to the surface, into both hydrophobic and hydrophilic parts of the lipid. This also occurs in the presence of cholesterol and ergosterol but, in contrast with the surface pressure study (Dynarowicz-Łątka et al. 2005) the amount of $\mathrm{AmB}$ incorporated when these two sterols are present is the same and depends on the surface pressure (Kamiński et al. 2014). For cholesterol, this apparent discrepancy is simply explained by monolayer corrugation and/or buckling or roughening which reduces the surface pressure. For the DPPC-ergosterol system, the monolayer is much less corrugated. The same orientation of AmB was observed in multibilayers investigated by neutron diffraction (Foglia et al. 2012).

Effect of lipid rafts

Biological membranes are not flat and homogenous as was imagined in the early 1970s (Singer and Nicolson 1972). The contemporary model is heterogeneous not only in structure but also in composition. The presence of sterolrich micro domains in the liquid ordered phase which freely float in a less sterol-rich liquid disordered phase, affect cellular transport and signal processes (Quest et al. 2004; Simons and Ikonen 1997). Such sterol-rich domains are called rafts. Ordering of lipid chain conformations is induced in rafts with a large sterol content (Fournier et al. 2008). This lipid ordering affects the affinity of AmB for liposomes, which in the solid phase is higher than in the liquid phase (indirect effect of sterol) (Bolard et al. 1981; Coutinho and Prieto 1995; Zumbuehl et al. 2004b). In these circumstances sterols contribute to ordering of aliphatic lipid chains, and ordering for ergosterol is greater than for cholesterol, because of its greater rigidity (Urbina et al. 1995; Hsueh et al. 2005; Czub and Baginski 2006). This is also true in the presence of AmB (Fournier et al. 2008). In the gel phase, AmB does not change the conformational order of lipid hydrocarbon chains; however, in the fluid phase the drug affects the structure of the lipid environment. According to the authors, AmB can initiate in-plane ergosterol redistribution, which is not observed for cholesterol. This is in accordance with an $\mathrm{H}^{1} \mathrm{NMR}$ study which shows that AmB, in the presence of ergosterol, interacts more strongly with the aliphatic lipid chains, whereas this is not observed for lipids containing cholesterol (Gabrielska et al. 2006). This is supported by the study by Umegawa et al. (2008), in which a substantial increase in the distance between AmB molecules was observed. For bilayers with cholesterol, no significant AmB-AmB distance changes were recorded, which must be related to its different location in the bilayer in comparison with the ergosterol system. Solid-state NMR experiments not only show that ergosterol interacts with AmB more strongly than with cholesterol in lipid environments but also the presence of ergosterol significantly affects AmB mobility in lipid bilayers (Matsumori et al. 2009). In summary, AmB may be accumulated more efficiently in lipid rafts which are more ordered than the disordered liquid phase. This different sterol distribution in the lipid bilayer in the presence of AmB can obviously affect channel formation. 


\section{Conclusion}

Despite very extensive investigations over the last 40 years, the mechanism of action of $\mathrm{AmB}$ is still not completely understood. Several studies suggest the antifungal activity of $\mathrm{AmB}$ is related to the presence of ergosterol, the main sterol of fungal cells. Toxicity toward mammal cells rich in cholesterol is smaller, but still high enough to cause many side effects. The action of AmB seems more complex than was imagined in the early 70s. The new models of oxidation burst or sterol sponge seem to be equally important for the antifungal properties as the well-known pore model. However, the old channel model is still attractive, especially because it explains in a simple way the whole range of effects, for example ion conductivity, AmB diffusion into membranes, and observed interactions with both lipids and sterols in artificial membranes. It is also clear that membranes of living organisms are more complex than model membranes, and the toxic effect of $\mathrm{AmB}$ toward fungal cells can also be related to the presence of rafts and membrane proteins. Experiments such as those conducted by the Burke and Murata groups in which specially modified sterols, AmB, and lipids were used can shed more light on the mechanism of action of AmB. However, Raman or fluorescence confocal microscopy studies of living yeasts treated with unmodified AmB should verify the relevance of the different models, especially that of oxidation burst and ergosterol sponge.

Acknowledgments I would like to thank Professor M. Gagos for fruitful discussions and Dr J. Czub and Professor M. Murata for important suggestions. This research was financed by the National Science Centre of Poland based on decision no. DEC-2012/05/B/NZ1/00037.

Open Access This article is distributed under the terms of the Creative Commons Attribution License which permits any use, distribution, and reproduction in any medium, provided the original author(s) and the source are credited

\section{References}

AbuSalah KM (1996) Amphotericin B: an update. Brit J Biomed Sci 53:122-133

Anderson TM, Clay MC, Cioffi AG, Diaz KA, Hisao GS, Tuttle MD, Nieuwkoop AJ, Comellas G, Maryum N, Wang S, Uno BE, Wildeman EL, Gonen T, Rienstra CM, Burke MD (2014) Amphotericin forms an extramembranous and fungicidal sterol sponge. Nat Chem Biol 10:400-406

Andres E, Tiphine M, Letscher-Bru V, Herbrecht R (2001) Review of new lipid formulations of amphotericin B. Rev Med Interne $22: 141-150$

Arczewska M, Gagoś M (2011) Molecular organization of antibiotic amphotericin B in dipalmitoylphosphatidylcholine monolayers induced by $\mathrm{K}^{+}$and $\mathrm{Na}^{+}$ions: the Langmuir technique study. Bba-Biomembranes 1808:2706-2713

Baginski M, Czub J (2009) Amphotericin B and its new derivativesmode of action. Curr Drug Metab 10:459-469
Baginski M, Resat H, Borowski E (2002) Comparative molecular dynamics simulations of amphotericin B-cholesterol/ergosterol membrane channels. Bba-Biomembranes 1567:63-78

Baginski M, Czub J, Sternal K (2006) Interaction of amphotericin B and its selected derivatives with membranes: molecular modeling studies. Chem Rec 6:320-332

Baran M, Borowski E, Mazerski J (2009) Molecular modeling of amphotericin B-ergosterol primary complex in water II. Biophys Chem 141:162-168

Barwicz J, Tancrede P (1997) The effect of aggregation state of amphotericin-B on its interactions with cholesterol- or ergosterol-containing phosphatidylcholine monolayers. Chem Phys Lipids 85:145-155

Barwicz J, Christian S, Gruda I (1992) Effects of the aggregation state of amphotericin B on its toxicity to mice. Antimicrob Agents Chemother 36:2310-2315

Barwicz J, Gruszecki WI, Gruda I (1993) Spontaneous organization of amphotericin-B in aqueous-medium. J Colloid Interf Sci 158:71-76

Barwicz J, Dumont I, Ouellet C, Gruda I (1998) Amphotericin B toxicity as related to the formation of oxidatively modified lowdensity lipoproteins. Biospectroscopy 4:135-144

Barwicz J, Gruda I, Tancrede P (2000) A kinetic study of the oxidation effects of amphotericin B on human low-density lipoproteins. FEBS Lett 465:83-86

Bolard J (1986a) How do the polyene macrolide antibiotics affect the cellular membrane-properties. Biochim Biophys Acta 864:257-304

Bolard J (1986b) Interaction of polyene antibiotics with membranelipids-physicochemical studies of the molecular-basis of selectivity. Drug Exp Clin Res 12:613-618

Bolard J, Cheron M (1982) Association of the polyene antibiotic amphotericin B with phospholipid vesicles: perturbation by temperature changes. Can J Biochem 60:782-789

Bolard J, Seigneuret M, Boudet G (1980a) Interaction between phospholipid-bilayer membranes and the polyene antibiotic amphotericin-B-lipid state and cholesterol content dependence. Biochim Biophys Acta 599:280-293

Bolard J, Seigneuret M, Boudet G (1980b) Interaction between phospholipid bilayer membranes and the polyene antibiotic amphotericin B: lipid state and cholesterol content dependence. Biochim Biophys Acta 599:280-293

Bolard J, Vertutcroquin A, Cybulska BE, Garybobo CM (1981) Transfer of the polyene antibiotic amphotericin-B between singlewalled vesicles of dipalmitoylphosphatidylcholine and egg-yolk phosphatidylcholine. Biochim Biophys Acta 647:241-248

Bolard J, Cleary JD, Kramer RE (2009) Evidence that impurities contribute to the fluorescence of the polyene antibiotic amphotericin B. J Antimicrob Chemoth 63:921-927

Bolard J, Cheron M, Cleary JD, Kramer RE (2011) The contribution of Raman scattering to the fluorescence of the polyene antibiotic amphotericin B. J Fluoresc 21:831-834

Brajtburg J, Elberg S, Schwartz DR, Vertut-Croquin A, Schlessinger D, Kobayashi GS, Medoff G (1985) Involvement of oxidative damage in erythrocyte lysis induced by amphotericin B. Antimicrob Agents Chemother 27:172-176

Brajtburg J, Powderly WG, Kobayashi GS, Medoff G (1990) Amphotericin B: current understanding of mechanisms of action. Antimicrob Agents Chemother 34:183-188

Brogden RN, Goa KL, Coukell AJ (1998) Amphotericin-B colloidal dispersion-a review of its use against systemic fungal infections and visceral leishmaniasis. Drugs 56:365-383

Brun S, Berges T, Poupard P, Vauzelle-Moreau C, Renier G, Chabasse D, Bouchara JP (2004) Mechanisms of azole resistance in petite mutants of Candida glabrata. Antimicrob Agents Chemother 48:1788-1796 
Brutyan RA, McPhie P (1996) On the one-sided action of amphotericin B on lipid bilayer membranes. J Gen Physiol 107:69-78

Carrillo-Munoz AJ, Giusiano G, Ezkurra PA, Quindos G (2006) Antifungal agents: mode of action in yeast cells. Revista espanola de quimioterapia : publicacion oficial de la Sociedad Espanola de Quimioterapia 19:130-139

Cass A, Finkelstein A, Krespi V (1970) The ion permeability induced in thin lipid membranes by the polyene antibiotics nystatin and amphotericin B. J Gen Physiol 56:100-124

Cereghetti DM, Carreira EM (2006) Amphotericin B: 50 years of chemistry and biochemistry. Synthesis-Stuttgart 6:914-942

Chang YG, Sun RG, Hao CC, Xue HJ, Han T, Wang XM (2010) Study on the interaction between cholesterol and amphotericin B in mixed monolayers. Acta Chim Sinica 68:2181-2185

Charbonneau C, Fournier I, Dufresne S, Barwicz J, Tancrede P (2001) The interactions of amphotericin B with various sterols in relation to its possible use in anticancer therapy. Biophys Chem 91:125-133

Cohen BE (1998) Amphotericin B toxicity and lethality: a tale of two channels. Int J Pharm 162:95-106

Cohen BE (2010) Amphotericin b membrane action: role for two types of ion channels in eliciting cell survival and lethal effects. J Membrane Biol 238:1-20

Cotero BV, Rebolledo-Antunez S, Ortega-Blake I (1998) On the role of sterol in the formation of the amphotericin B channel. Biochim Biophys Acta 1375:43-51

Coutinho A, Prieto M (1995) Self-association of the polyene antibiotic nystatin in dipalmitoylphosphatidylcholine vesicles: a timeresolved fluorescence study. Biophys J 69:2541-2557

Croatt MP, Carreira EM (2011) Probing the role of the mycosamine C2'-OH on the activity of amphotericin B. Org Lett 13:1390-1393

Czub J, Baginski M (2006) Comparative molecular dynamics study of lipid membranes containing cholesterol and ergosterol. Biophys J 90:2368-2382

Czub J, Neumann A, Borowski E, Baginski M (2009) Influence of a lipid bilayer on the conformational behavior of amphotericin B derivatives-a molecular dynamics study. Biophys Chem 141:105-116

de Kruijff B, Demel RA (1974) Polyene antibiotic-sterol interactions in membranes of acholeplasma laidlawii cells and lecithin liposomes. 3. Molecular structure of the polyene antibiotic-cholesterol complexes. Biochim Biophys Acta 339:57-70

Diezi TA, Kwon G (2012) Amphotericin B/sterol co-loaded PEGphospholipid micelles: effects of sterols on aggregation state and hemolytic activity of amphotericin B. Pharm Res 29:1737-1744

Dynarowicz-Łątka P, Minones J, Conde O, Casas M, Iribarnegaray E (2005) BAM studies on the penetration of amphotericin B into lipid mixed monolayers of cellular membranes. Appl Surf Sci 246:334-341

Dynarowicz-Łątka P, Seoane R, Miñones J Jr, Velo M, Miñones J (2003) Study of penetration of amphotericin B into cholesterol or ergosterol containing dipalmitoyl phosphatidylcholine Langmuir monolayers. Colloids Surf, B 27:249-263

Fanos V, Cataldi L (2000) Amphotericin B-induced nephrotoxicity: a review. J Chemother 12:463-470

Fanos V, Cataldi L (2001) Renal transport of antibiotics and nephrotoxicity: a review. J Chemother 13:461-472

Fanos V, Cuzzolin L, Atzei A, Testa M (2007) Antibiotics and antifungals in neonatal intensive care units: a review. J Chemother 19:5-20

Finkelstein A, Holz R (1973) Aqueous pores created in thin lipid membranes by the polyene antibiotics nystatin and amphotericin B. Membranes 2:377-408

Foglia F, Drake AF, Terry AE, Rogers SE, Lawrence MJ, Barlow DJ (2011) Small-angle neutron scattering studies of the effects of amphotericin B on phospholipid and phospholipid-sterol membrane structure. Biochim Biophys Acta 1808:1574-1580

Foglia F, Lawrence MJ, Deme B, Fragneto G, Barlow D (2012) Neutron diffraction studies of the interaction between amphotericin B and lipid-sterol model membranes. Sci Rep 2:778

Fournier I, Barwicz J, Auger M, Tancrede P (2008) The chain conformational order of ergosterol- or cholesterol-containing DPPC bilayers as modulated by Amphotericin B: a FTIR study. Chem Phys Lipids 151:41-50

Fujii G, Chang JE, Coley T, Steere B (1997) The formation of amphotericin B ion channels in lipid bilayers. Biochemistry 36:4959-4968

Gabrielska J, Gagoś M, Gubernator J, Gruszecki WI (2006) Binding of antibiotic amphotericin B to lipid membranes: a 1H NMR study. FEBS Lett 580:2677-2685

Gagoś M, Arczewska M (2010) Spectroscopic studies of molecular organization of antibiotic amphotericin B in monolayers and dipalmitoylphosphatidylcholine lipid multibilayers. Biochim Biophys Acta 1798:2124-2130

Gagoś M, Arczewska M (2012) FTIR spectroscopic study of molecular organization of the antibiotic amphotericin $\mathrm{B}$ in aqueous solution and in DPPC lipid monolayers containing the sterols cholesterol and ergosterol. Eur Biophys J : EBJ 41:663-673

Gagoś M, Czernel G (2014) Oxidized forms of polyene antibiotic amphotericin B. Chem Phys Lett 8:5-9

Gagoś M, Gruszecki WI (2008) Organization of polyene antibiotic amphotericin B at the argon-water interface. Biophys Chem 137:110-115

Gagoś M, Gabrielska J, Dalla Serra M, Gruszecki WI (2005) Binding of antibiotic amphotericin B to lipid membranes: monomolecular layer technique and linear dichroism-FTIR studies. Mol Membr Biol 22:433-442

Gagoś M, Kamiński D, Arczewska M, Krajnik B, Mackowski S (2012) Spectroscopic evidence for self-organization of N-iodoacetylamphotericin B in crystalline and amorphous phases. J Phys Chem B 116:12706-12713

Gallis HA, Drew RH, Pickard WW (1990) Amphotericin B: 30 years of clinical experience. Rev Infect Dis 12:308-329

Ganis P, Avitabil G, Mechlins W, Schaffne Cp (1971) Polyene macrolide antibiotic amphotericin-B-Crystal structure of $\mathrm{N}$-iodoacetyl derivative. J Am Chem Soc 93:4560

Gomez-Lopez A, Buitrago MJ, Rodriguez-Tudela JL, Cuenca-Estrella M (2011) In vitro antifungal susceptibility pattern and ergosterol content in clinical yeast strains. Revista iberoamericana de micologia 28:100-103

Gray KC, Palacios DS, Dailey I, Endo MM, Uno BE, Wilcock BC, Burke MD (2012) Amphotericin primarily kills yeast by simply binding ergosterol. Proc Natl Acad Sci 109:2234-2239

Gruszecki WI, Gagoś M, Kernen P (2002) Polyene antibiotic amphotericin B in monomolecular layers: spectrophotometric and scanning force microscopic analysis. FEBS Lett 524:92-96

Gruszecki WI, Gagoś M, Herec M, Kernen P (2003) Organization of antibiotic amphotericin B in model lipid membranes. A mini review. Cell Mol Biol Lett 8:161-170

Gruszecki WI, Luchowski R, Gagoś M, Arczewska M, Sarkar P, Herec M, Mysliwa-Kurdziel B, Strzalka K, Gryczynski I, Gryczynski Z (2009) Molecular organization of antifungal antibiotic amphotericin $\mathrm{B}$ in lipid monolayers studied by means of fluorescence lifetime imaging microscopy. Biophys Chem 143:95-101

Gruszecki WI, Luchowski R, Wasko P, Gryczynski Z, Gryczynski I (2012) Molecular organization of polyene antibiotic amphotericin B studied by means of fluorescence technique. Methods Mol Biol 875:57-65

Hac-Wydro K, Dynarowicz-Łątka P (2006) Interaction between nystatin and natural membrane lipids in Langmuir monolayers- the 
role of a phospholipid in the mechanism of polyenes mode of action. Biophys Chem 123:154-161

Hac-Wydro K, Dynarowicz-Łątka P, Grzybowska J, Borowski E (2005a) How does the $\mathrm{N}$-acylation and esterification of amphotericin $\mathrm{B}$ molecule affect its interactions with cellular membrane components-the Langmuir monolayer study. Colloids Surf, B 46:7-19

Hac-Wydro K, Dynarowicz-Łątka P, Grzybowska J, Borowski E (2005b) Interactions of amphotericin B derivative of low toxicity with biological membrane components-the Langmuir monolayer approach. Biophys Chem 116:77-88

Hac-Wydro K, Dynarowicz-Łątka P, Grzybowska J, Borowski E (2005c) N-(1-piperidinepropionyl)amphotericin B methyl ester (PAME) - a new derivative of the antifungal antibiotic amphotericin B: searching for the mechanism of its reduced toxicity. $\mathrm{J}$ Colloid Interf Sci 287:476-484

Hamill RJ (2013) Amphotericin B formulations: a comparative review of efficacy and toxicity. Drugs 73:919-934

Hargreaves PL, Nguyen TS, Ryan RO (2006) Spectroscopic studies of amphotericin B solubilized in nanoscale bilayer membranes. Biochim Biophys Acta 1758:38-44

Hartsel S, Bolard J (1996) Amphotericin B: new life for an old drug. Trends Pharmacol Sci 17:445-449

Hirano M, Takeuchi Y, Matsumori N, Murata M, Ide T (2011) Channels formed by amphotericin B covalent dimers exhibit rectification. J Membrane Biol 240:159-164

HsuChen C-C, Feingold DS (1973) Polyene antibiotic action on lecithin liposomes: effect of cholesterol and fatty acyl chains. Biochem Biophys Res Comm 51:972-978

Hsueh YW, Gilbert K, Trandum C, Zuckermann M, Thewalt J (2005) The effect of ergosterol on dipalmitoylphosphatidylcholine bilayers: a deuterium NMR and calorimetric study. Biophys J 88:1799-1808

Jarzembska KN, Kamiński D, Hoser AA, Malinska M, Senczyna B, Wozniak K, Gagoś M (2012) Controlled crystallization, structure, and molecular properties of iodoacetylamphotericin B. Cryst Growth Des 12:2336-2345

Jeon OY, Carreira EM (2010) Differential interaction of an AmB analogue and ergosterol in enantiomeric membranes. Org Lett 12:1772-1775

Kamiński DM, Czernel G, Murphy B, Runge B, Magnussen OM, Gagoś M (2014) Effect of cholesterol and ergosterol on the antibiotic amphotericin B interactions witch dipalmitoylphosphatidylcholine monolayers: X-ray reflectivity study BBA-Biomembranes doi:10.1016/j.bbamem.2014.08.004

Kasai Y, Matsumori N, Umegawa Y, Matsuoka S, Ueno H, Ikeuchi H, Oishi T, Murata M (2008) Self-assembled amphotericin B is probably surrounded by ergosterol: bimolecular interactions as evidenced by solid-state NMR and CD spectra. Chem-Eur J 14:1178-1185

Kasai Y, Matsumori N, Ueno H, Nonomura K, Yano S, Michio M, Oishi T (2011) Synthesis of 6-F-ergosterol and its influence on membrane-permeabilization of amphotericin $\mathrm{B}$ and amphidinol 3. Org Biomol Chem 9:1437-1442

Katsu T, Imamura T, Komagoe K, Masuda K, Mizushima T (2007) Simultaneous measurements of $\mathrm{K}^{+}$and calcein release from liposomes and the determination of pore size formed in a membrane. Anal Sci 23:517-522

Katsu T, Okada S, Imamura T, Komagoe K, Masuda K, Inoue T, Nakao S (2008) Precise size determination of amphotericin $\mathrm{B}$ and nystatin channels formed in erythrocyte and liposomal membranes based on osmotic protection experiments. Anal Sci : Int J Jpn Soc Anal Chem 24:1551-1556

Lamy-Freund MT, Ferreira VF, Schreier S (1985) Mechanism of inactivation of the polyene antibiotic amphotericin B. Evidence for radical formation in the process of autooxidation. $\mathrm{J}$ antibiot $38: 753-757$
Lemke A, Kiderlen A, Kayser O (2005) Amphotericin B. Appl Microbiol Biot 68:151-162

Man D, Olchawa R (2013) Two-step impact of Amphotericin B (AmB) on lipid membranes: eSR experiment and computer simulations. J Liposome Res 23:327-335

Marty A, Finkelstein A (1975) Pores formed in lipid bilayer membranes by nystatin, differences in its one-sided and two-sided action. J Gen Physiol 65:515-526

Matsumori N, Eiraku N, Matsuoka S, Oishi T, Murata M, Aoki T, Ide T (2004) An amphotericin B-ergosterol covalent conjugate with powerful membrane permeabilizing activity. Chem Biol 11:673-679

Matsumori N, Sawada Y, Murata M (2005) Mycosamine orientation of amphotericin B controlling interaction with ergosterol: steroldependent activity of conformation-restricted derivatives with an amino-carbonyl bridge. J Am Chem Soc 127:10667-10675

Matsumori N, Sawada Y, Murata M (2006) Large molecular assembly of amphotericin B formed in ergosterol-containing membrane evidenced by solid-state NMR of intramolecular bridged derivative. J Am Chem Soc 128:11977-11984

Matsumori N, Tahara K, Yamamoto H, Morooka A, Doi M, Oishi T, Murata M (2009) Direct interaction between amphotericin B and ergosterol in lipid bilayers as revealed by H-2 NMR spectroscopy. J Am Chem Soc 131:11855-11860

Matsuoka S, Murata M (2002) Cholesterol markedly reduces ion permeability induced by membrane-bound amphotericin B. BbaBiomembranes 1564:429-434

Matsuoka S, Murata M (2003) Membrane permeabilizing activity of amphotericin B is affected by chain length of phosphatidylcholine added as minor constituent. Bba-Biomembranes 1617:109-115

Matsuoka S, Matsumori N, Murata M (2003) Amphotericin B-phospholipid covalent conjugates: dependence of membrane-permeabilizing activity on acyl-chain length. Org Biomol Chem $1: 3882-3884$

Mazerski J, Bolard J, Borowski E (1982) Self-association of some polyene macrolide antibiotics in aqueous-media. Biochim Biophys Acta 719:11-17

Menez C, Buyse M, Besnard M, Farinotti R, Loiseau PM, Barratt G (2006) Interaction between miltefosine and amphotericin B: consequences for their activities towards intestinal epithelial cells and Leishmania donovani promastigotes in vitro. Antimicrob Agents Chemother 50:3793-3800

Minones J, Carrera C, Dynarowicz-Łątka P, Minones J, Conde O, Seoane R, Patino JMR (2001) Orientational changes of amphotericin $\mathrm{B}$ in Langmuir monolayers observed by Brewster angle microscopy. Langmuir 17:1477-1482

Minones J, Minones J, Conde O, Patino JMR, Dynarowicz-Łątka P (2002) Mixed monolayers of amphotericin B-dipalmitoyl phosphatidyl choline: study of complex formation. Langmuir 18:2817-2827

Minones J, Minones J, Rodriguez-Patino JM, Conde O, Iribarnegaray E (2003) Miscibility of amphotericin B-dipalmitoyl phosphatidyl serine mixed monolayers spread on the air/water interface. J Phys Chem B 107:4189-4195

Miñones J Jr, Conde O, Dynarowicz-Łątka P, Casas M (2005) Penetration of amphotericin B into DOPC monolayers containing sterols of cellular membranes. Colloids Surf A 270-271:129-137

Moen MD, Lyseng-Williamson KA, Scott LJ (2009) Liposomal amphotericin B: a review of its use as empirical therapy in febrile neutropenia and in the treatment of invasive fungal infections. Drugs 69:361-392

Mouri R, Konoki K, Matsumori N, Oishi T, Murata M (2008) Complex formation of amphotericin B in sterol-containing membranes as evidenced by surface plasmon resonance. Biochemistry $47: 7807-7815$ 
Neumann A, Czub J, Baginski M (2009) On the possibility of the amphotericin B-sterol complex formation in cholesterol-and ergosterol-containing lipid bilayers: a molecular dynamics study. J Phys Chem B 113:15875-15885

Neumann A, Baginski M, Czub J (2010) How do sterols determine the antifungal activity of amphotericin B? free energy of binding between the drug and its membrane targets. J Am Chem Soc 132:18266-18272

Neumann A, Baginski M, Czub J (2013a) Exploring amphotericin B-membrane interactions: free energy simulations. Biophys $\mathbf{J}$ 104:250a-250a

Neumann A, Baginski M, Winczewski S, Czub J (2013b) The effect of sterols on amphotericin B self-aggregation in a lipid bilayer as revealed by free energy simulations. Biophys J 104:1485-1494

O'Shaughnessy EM, Lyman CA, Walsh TJ (2009) Amphotericin B: Polyene Resistance Mechanisms. In: Mayers D (ed) Antimicrobial drug resistance: mechanisms of drug resistance, vol 1. Humana Press, a part of Springer Science+Business Media, pp 299-304

Ostroumova OS, Efimova SS, Schagina LV (2012) Probing amphotericin B single channel activity by membrane dipole modifiers. PLoS One 7:e30261

Palacios DS, Dailey I, Siebert DM, Wilcock BC, Burke MD (2011) Synthesis-enabled functional group deletions reveal key underpinnings of amphotericin B ion channel and antifungal activities. Proc Natl Acad Sci USA 108:6733-6738

Paquet V, Carreira EM (2006) Significant improvement of antifungal activity of polyene macrolides by bisalkylation of the mycosamine. Org Lett 8:1807-1809

Paquet MJ, Fournier I, Barwicz J, Tancrede P, Auger M (2002) The effects of amphotericin B on pure and ergosterol- or cholesterol-containing dipalmitoylphosphatidylcholine bilayers as viewed by H-2 NMR. Chem Phys Lipids 119:1-11

Paquet V, Zumbuehl A, Carreira EM (2006) Biologically active amphotericin B-calix[4] arene conjugates. Bioconjugate Chem 17:1460-1463

Pham TTH, Barratt G, Michel JP, Loiseau PM, Saint-Pierre-Chazalet M (2013) Interactions of antileishmanial drugs with monolayers of lipids used in the development of amphotericin B-miltefosine-loaded nanocochleates. Colloids Surf B 106:224-233

Quest AF, Leyton L, Parraga M (2004) Caveolins, caveolae, and lipid rafts in cellular transport, signaling, and disease. Biochem Cell Biol 82:129-144

Ramanandraibe E, Younsi M, Coulon J, Loppinet V, Hakkou A, Bonaly R (1998) Implication of cell wall constituents in the sensitivity of Kluyveromyces lactis strains to amphotericin B. Res Microbiol 149:109-118

Rapp RP, Gubbins PO, Evans ME (1997) Amphotericin B lipid complex. Ann Pharmacother 31:1174-1186

Reeves EP, Murphy T, Daly P, Kavanagh K (2004) Amphotericin B enhances the synthesis and release of the immunosuppressive agent gliotoxin from the pulmonary pathogen Aspergillus fumigatus. J Med Microbiol 53:719-725

Saint-Pierre-Chazalet M, Thomas C, Dupeyrat M, Gary-Bobo CM (1988) Amphotericin B-sterol complex formation and competition with egg phosphatidylcholine: a monolayer study. Biochim Biophys Acta 944:477-486

Sangalli-Leite F, Scorzoni L, Mesa-Arango AC, Casas C, Herrero E, Gianinni MJSM, Rodriguez-Tudela JL, Cuenca-Estrella M, Zaragoza O (2011) Amphotericin B mediates killing in Cryptococcus neoformans through the induction of a strong oxidative burst. Microbes Infect 13:457-467

Sanglard D, Odds FC (2002) Resistance of Candida species to antifungal agents: molecular mechanisms and clinical consequences. Lancet Infect Dis 2:73-85
Schneiter R, Brugger B, Sandhoff R, Zellnig G, Leber A, Lampl M, Athenstaedt K, Hrastnik C, Eder S, Daum G, Paltauf F, Wieland FT, Kohlwein SD (1999) Electrospray ionization tandem mass spectrometry (ESI-MS/MS) analysis of the lipid molecular species composition of yeast subcellular membranes reveals acyl chain-based sorting/remodeling of distinct molecular species en route to the plasma membrane. J Cell Biol 146:741-754

Seitz LM, Sauer DB, Burroughs R, Mohr HE, Hubbard JD (1979) Ergosterol as a measure of fungal growth. Phytopathology 69:1202-1203

Seoane R, Minones J, Conde O, Casas M, Iribarnegaray E (1998) Molecular organisation of amphotericin $\mathrm{B}$ at the air-water interface in the presence of sterols: a monolayer study. BBABiomembranes 1375:73-83

Seoane R, Minones J, Conde O, Casas M, Iribarnegaray E (1999a) Interaction between amphotericin $\mathrm{B}$ and sterols in monolayers. Mixed Films of ergosterol-amphotericin B. Langmuir 15:3570-3573

Seoane R, Minones J, Conde O, Iribarnegaray E, Casas M (1999b) Interactions between amphotericin-B and sterols in monolayers. Mixed films of amphotericin B-cholesterol. Langmuir 15:5567-5573

Shervani Z, Etori H, Taga K, Yoshida T, Okabayashi H (1996) Aggregation of polyene antibiotics as studied by electronic absorption and circular dichroism spectroscopies. Colloid Surf B 7:31-38

Simons K, Ikonen E (1997) Functional rafts in cell membranes. Nature 387:569-572

Singer SJ, Nicolson GL (1972) The fluid mosaic model of the structure of cell membranes. Science 175:720-731

Slisz M, Cybulska B, Mazerski J, Grzybowska J, Borowski E (2004) Studies of the effects of antifungal cationic derivatives of amphotericin B on human erythrocytes. J Antibiot 57:669-678

Slisz M, Cybulska B, Grzybowska J, Czub J, Prasad R, Borowski E (2007) Amphotericin B and its nontoxic derivative - MFAME overcome MDR of fungi by not being substrates of efflux pumps. Drug Future 32:116-116

Sokol-Anderson ML, Brajtburg J, Medoff G (1986) Amphotericin B-induced oxidative damage and killing of Candida albicans. $\mathrm{J}$ Infect Dis 154:76-83

Sokol-Anderson M, Sligh JE Jr, Elberg S, Brajtburg J, Kobayashi GS, Medoff G (1988) Role of cell defense against oxidative damage in the resistance of Candida albicans to the killing effect of amphotericin B. Antimicrob Agents Chemother 32:702-705

Sternal K, Czub J, Baginski M (2004) Molecular aspects of the interaction between amphotericin $\mathrm{B}$ and a phospholipid bilayer: molecular dynamics studies. J Mol Model 10:223-232

Strachecka A, Borsuk G, Olszewski K, Paleolog J, Gagoś M, Chobotow J, Nawrocka A, Gryzinska M, Bajda M (2012) The effect of amphotericin $\mathrm{b}$ on the lifespan, body-surface protein concentrations, and DNA methylation levels of honey bees (Apis mellifera). J Apic Sci 56:107-113

Sykora JC, Neely WC, Vodyanoy V (2004) Thermodynamic characteristics of mixed monolayers of amphotericin B and cholesterol. J Colloid Interface Sci 276:60-67

te Welscher YM, ten Napel HH, Balague MM, Souza CM, Riezman H, de Kruijff B, Breukink E (2008) Natamycin blocks fungal growth by binding specifically to ergosterol without permeabilizing the membrane. J Biol Chem 283:6393-6401

Teerlink T, de Kruijff B, Demel RA (1980) The action of pimaricin, etruscomycin and amphotericin B on liposomes with varying sterol content. Biochim Biophys Acta 599:484-492

Tevyashova AN, Olsufyeva EN, Solovieva SE, Printsevskaya SS, Reznikova MI, Trenin AS, Galatenko OA, Treshalin ID, Pereverzeva ER, Mirchink EP, Isakova EB, Zotchev SB, Preobrazhenskaya MN (2013) Structure-antifungal activity relationships 
of polyene antibiotics of the amphotericin B group. Antimicrob Agents Chemother 57:3815-3822

Tiphine M, Letscher-Bru V, Herbrecht R (1999) Amphotericin B and its new formulations: pharmacologic characteristics, clinical efficacy, and tolerability. Transplant Infect Dis : Off J Transplant Soc 1:273-283

Umegawa Y, Matsumori N, Oishi T, Murata M (2008) Ergosterol increases the intermolecular distance of amphotericin $\mathrm{b}$ in the membrane-bound assembly as evidenced by solid-state NMR. Biochem 47:13463-13469

Umegawa Y, Adachi T, Matsumori N, Murata M (2012a) Possible conformation of amphotericin B dimer in membrane-bound assembly as deduced from solid-state NMR. Bioorgan Med Chem 20:5699-5704

Umegawa Y, Nakagawa Y, Tahara K, Tsuchikawa H, Matsumori N, Oishi T, Murata M (2012b) Head-to-tail interaction between amphotericin $\mathrm{b}$ and ergosterol occurs in hydrated phospholipid membrane. Biochem 51:83-89

Urbina JA, Pekerar S, Le HB, Patterson J, Montez B, Oldfield E (1995) Molecular order and dynamics of phosphatidylcholine bilayer membranes in the presence of cholesterol, ergosterol and lanosterol: a comparative study using $2 \mathrm{H}-$, 13C- and 31PNMR spectroscopy. Biochem Biophys Acta 1238:163-176

Vandeputte P, Tronchin G, Larcher G, Ernoult E, Berges T, Chabasse D, Bouchara JP (2008) A nonsense mutation in the ERG6 gene leads to reduced susceptibility to polyenes in a clinical isolate of Candida glabrata. Antimicrob Agents Chemother 52:3701-3709

Vandeputte P, Pineau L, Larcher G, Noel T, Brethes D, Chabasse D, Bouchara JP (2011) Molecular mechanisms of resistance to 5-fluorocytosine in laboratory mutants of Candida glabrata. Mycopathologia 171:11-21

Venegas B, Gonzalez-Damian J, Celis H, Ortega-Blake I (2003) Amphotericin B channels in the bacterial membrane: role of sterol and temperature. Biophys J 85:2323-2332

Vertutcroquin A, Bolard J, Chabbert M, Garybobo C (1983) Differences in the interaction of the polyene antibiotic amphotericin-b with cholesterol-containing or ergosterol-containing phospholipid-vesicles-a circular-dichroism and permeability Study. Biochem 22:2939-2944

Volmer AA, Carreira EM (2010) Active amphotericin B derivatives position the mycosamine in two radial orientations. Chem Bio Chem :Eur J Chem Biol 11:778-781

Wilcock BC, Uno BE, Bromann GL, Clark MJ, Anderson TM, Burke MD (2012) Electronic tuning of site-selectivity. Nat Chem 4:996-1003

Wilcock BC, Endo MM, Uno BE, Burke MD (2013) C2'-OH of amphotericin B plays an important role in binding the primary sterol of human cells but not yeast cells. J Am Chem Soc 135:8488-8491

Wong-Beringer A, Jacobs RA, Guglielmo BJ (1998) Lipid formulations of amphotericin B: clinical efficacy and toxicities. Clin Infect Dis 27:603-618

Yang TS, Ou KL, Peng PW, Liou BC, Wang WT, Huang YC, Tsai CM, Su CH (2013) Quantifying membrane permeability of amphotericin B ion channels in single living cells. Biochim Biophys Acta 1828:1794-1801

Yilma S, Cannon-Sykora J, Samoylov A, Lo T, Liu N, Brinker CJ, Neely WC, Vodyanoy V (2007) Large-conductance cholesterolamphotericin B channels in reconstituted lipid bilayers. Biosens Bioelectron 22:1359-1367

Younsi M, Ramanandraibe E, Bonaly R, Donner M, Coulon J (2000) Amphotericin B resistance and membrane fluidity in Kluyveromyces lactis strains. Antimicrob Agents Chemother 44:1911-1916

Zumbuehl A, Jeannerat D, Martin SE, Sohrmann M, Stano P, Vigassy T, Clark DD, Hussey SL, Peter M, Peterson BR, Pretsch E, Walde P, Carreira EM (2004a) An amphotericin B-fluorescein conjugate as a powerful probe for biochemical studies of the membrane. Angew Chem 43:5181-5185

Zumbuehl A, Stano P, Heer D, Walde P, Carreira EM (2004b) Amphotericin $\mathrm{B}$ as a potential probe of the physical state of vesicle membranes. Org Lett 6:3683-3686

Zumbuehl A, Stano P, Sohrmann M, Dietiker R, Peter M, Carreira EM (2009) Synthesis and investigation of tryptophan-amphotericin B conjugates. Chem Bio Chem : Eur J Chem Biol 10:1617-1620 